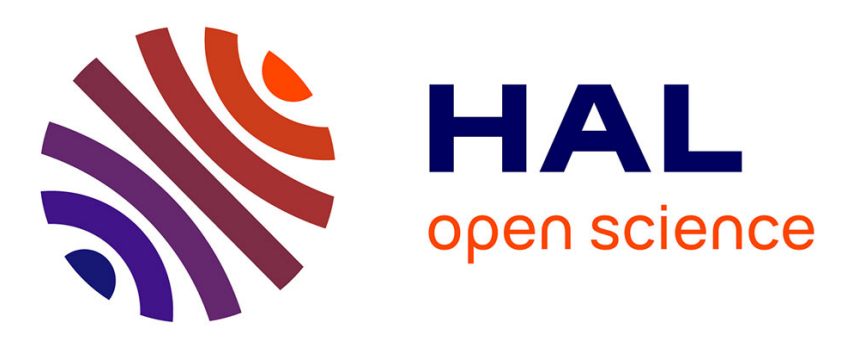

\title{
Numerical modeling of coupled phenomena in a mechanically stirred molten-glass bath heated by induction
}

Laetitia Jacoutot, Yves Fautrelle, A. Gagnoud, Patrice Brun, Jacques Lacombe

\section{To cite this version:}

Laetitia Jacoutot, Yves Fautrelle, A. Gagnoud, Patrice Brun, Jacques Lacombe. Numerical modeling of coupled phenomena in a mechanically stirred molten-glass bath heated by induction. Chemical Engineering Science, 2008, 63 (9), pp.2391-2401. 10.1016/j.ces.2008.01.026 . cea-02515781

\section{HAL Id: cea-02515781 https://hal-cea.archives-ouvertes.fr/cea-02515781}

Submitted on 23 Mar 2020

HAL is a multi-disciplinary open access archive for the deposit and dissemination of scientific research documents, whether they are published or not. The documents may come from teaching and research institutions in France or abroad, or from public or private research centers.
L'archive ouverte pluridisciplinaire $\mathbf{H A L}$, est destinée au dépôt et à la diffusion de documents scientifiques de niveau recherche, publiés ou non, émanant des établissements d'enseignement et de recherche français ou étrangers, des laboratoires publics ou privés. 


\title{
Numerical modelling of natural convection in molten glass heated by induction
}

\author{
Laetitia Jacoutot $^{1 *, * *}$, Patrice Brun*, Annie Gagnoud**, Yves Fautrelle ${ }^{* *}$ \\ * CEA-Valrhô Marcoule, BP 17171, 30207 Bagnols sur Cèze Cedex, France \\ **EPM-Madylam, ENSHMG, BP 95, 38402 Saint Martin d'Hères, France
}

\begin{abstract}
A new vitrification process based on a cold crucible heated by direct induction has been developed by CEA. This process is characterized by the cooling of all the walls and by currents directly induced inside the molten glass. This paper presents a global modelling of phenomena which take place in vitrification in a cold crucible. Electromagnetic, thermal and hydrodynamic phenomena are modelled within the molten glass. The thermohydrodynamic aspects are solved by FLUENT software (distributed by Fluent France) and the electromagnetic aspects by OPHELIE (EPM program based on integral methods). The numerical studies are validated using experimental results obtained from pilot vitrification facilities.
\end{abstract}

Keywords: coupled modelling, electromagnetism, thermohydrodynamics, thermal convection, vitrification.

\section{Introduction}

Since the late 1950s, many research and development programs have focused on the problem of nuclear waste reprocessing and containment. Vitrification has shown its capability for safe long-term conditioning of high-level radioactive waste. This process consists of incorporating the

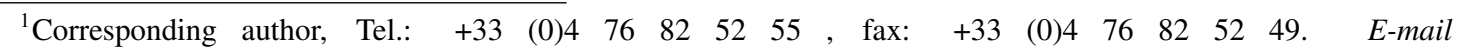
adress:laetitia.jacoutot@hmg.inpg.fr
} 
ultimate waste in molten glass. However, the continuous vitrification process used by Cogema at La Hague in France is not suitable to meet new needs, including the vitrification of other types of waste and the reduction of waste volumes. Vitrification materials and processes must be adapted to handle waste with higher fuel burnup values and liquid solutions from the reprocessing of legacy fuel. Direct-induction cold-crucible vitrification would appear to offer a possible solution. This technology is under investigation at Marcoule and is intended to replace metal pots in one of the six vitrification lines of the plant at La Hague. The direct-induction cold-crucible process is distinguished by an inductor supplied by a sinusoidal current and by the cooling of all the walls (figure 1). For a cold crucible with a $650 \mathrm{~mm}$ diameter, the inductor surrounding the crucible is connected to a high-frequency current generator putting out $400 \mathrm{~kW}$ at a frequency of 300 $\mathrm{kHz}$. The process is based on the induction of electric currents directly in the glass. The energy dissipated by the induced currents due to the Joule effect melts the glass. The advantages of the cold crucible are mainly related to the formation of a thin layer of solidified glass. This solidified glass forms a "skull melter" that insulates the cold melter walls from the molten glass. Thus, the crucible walls are not corroded by the molten glass and in turn the molten glass is not contaminated. Cold-crucible vitrification greatly extends the service life of the melter, thereby decreasing the production of secondary technological waste.

Numerical modelling is extremely useful in the operation and optimization of the vitrification facility. In fact, it is necessary to understand the phenomena taking place in vitrification in order to control the distribution of thermal gradients and convection zones within the bath. Until now, only a few studies have been devoted to finding numerical solutions to this process. The main difficulty encountered is related to the large thermal variations of the physical properties of the glass, requiring coupling of the electromagnetic, hydrodynamic and thermal aspects. In their study, Servant et al. [1] did not take fluid flow into account and only thermal and electromagnetic 
phenomena were coupled. Schiff $[2,3]$ modelled all three aspects but electromagnetic modelling neglected border effects. Modelling of the forming process of TV-panels is presented by Op Den Camp [4] but the glass is not heated by direct induction. A heat flux distribution is used to describe combustion over the glass surface. In the present study, the thermohydrodynamic and electromagnetic models are coupled and a complete modelling is obtained. In addition, because of the complexity of the vitrification process in a cold crucible and due to the lack of sensors and accurate analysing techniques to measure temperature and velocity field within the glass bath, no quantitative description has been carried out so far. In this paper, the validation of the numerical results using experimental results obtained from pilot vitrification facilities is presented.

\section{Mathematical models}

\subsection{Thermohydrodynamic model}

Hypothesis and equations The thermohydrodynamic aspects are solved only within the glass bath. The Rayleigh number $R a=g \beta \Delta T h^{3} / \nu \alpha$ does not exceed $10^{5}$ and the Prandtl number $\operatorname{Pr}=\nu / \alpha$ is $10^{3}$. The flow is therefore assumed to be laminar and steady by analogy with flow driven by thermal convection in enclosures. The steady flow hypothesis is discussed in section 3 . The Boussinesq assumption is used to model buoyancy. This model treats density as a constant value in all solved equations, except for the buoyancy term in the momentum equation where $\rho$ is defined by $\rho=\rho_{0}\left(1-\beta\left(T-T_{0}\right)\right)$. This approximation is accurate because changes in actual density are small; specifically, the Boussinesq approximation is valid because $\beta\left(T-T_{0}\right)<<1$. All the other physical properties (viscosity, specific heat, electrical and thermal conductivities) are defined by temperature dependence based on a piecewise-linear function. Laplace forces due to induced currents and electromagnetic field in the glass are neglected. The magnitudes of these forces are low compared with the forces generated by thermal convection [5]. The modelled glass 
show strong absorption, it is almost completely nontransparent even for thin layers. The heat transfer inside the glass is therefore only determined by heat conductivity, the internal radiation in the glass bath is neglected. The fluid is assumed to be Newtonian. Experimental studies show that glass behaves as a Newtonian fluid at high temperature but below the glass transition region its rheological behavior is complex. However, this assumption is not very restrictive because velocities are very small in the cold regions. The equations for laminar steady flow are the continuity (1), the Navier Stokes (2) and thermal energy (3) equations:

$$
\begin{gathered}
\vec{\nabla} \cdot \vec{u}=0, \\
\rho_{0}(\vec{u} \cdot \vec{\nabla}) \vec{u}=-\vec{\nabla} p^{*}-\vec{\nabla} \cdot(\mu \vec{\nabla} \vec{u})-\rho_{0} \beta\left(T-T_{0}\right) \vec{g}, \\
\rho_{0} \vec{\nabla} \cdot\left(C_{p} T \vec{u}\right)=\vec{\nabla} \cdot(\lambda \vec{\nabla} T)+Q_{t h},
\end{gathered}
$$

where $p^{*}$ is defined as $p^{*}=p+\rho_{0} g z$. The source term $Q_{t h}$ in the thermal energy equation represents the density of the Joule power. It is calculated by the electromagnetic code according to the relation (4).

$$
Q_{t h}=\frac{|j|^{2}}{2 \sigma}
$$

where $|j|$ denotes the modulus of current density.

Boundary conditions Concerning thermal boundary conditions, radiative and convective heat transfer is taken into account at the free surface. The heat flux through the free surface is calculated as

$$
\varphi=\epsilon \sigma_{s b}\left(T_{s}^{4}-T_{a}^{4}\right)+h_{s}\left(T_{s}-T_{a}\right)
$$

Heat losses through the walls (crucible and base) are expressed by the following equation:

$$
\varphi=h_{w}\left(T_{w}-T_{c}\right)
$$


Equation (6) includes the contact resistance between the glass and the walls and the heat exchange between the walls and the cooling water.

The velocity boundary conditions are chosen to correspond to the physical model, i.e. no-slip boundary conditions along solid boundaries and a slip boundary condition on top of the glass bath.

Numerical method The thermohydrodynamic aspects has been modelled using the FLUENT CFD software, and its accompanying mesh generation software, Gambit. The governing equations are solved sequentially with a finite-volume discretization process. In this segregated solution method each discrete equation is linearized implicitly with respect to that equation's dependent variable. For the convection terms of each equations (momentum and energy) a second-order discretization is used. The diffusion terms are central-differenced and second-order accurate. The interpolation of the pressure terms is preformed by the PRESTO (PREssure STaggering Option) scheme. The SIMPLEC (Semi-Implicit Method for Pressure-Linked Equations Consistent) algorithm is used for introducing pressure into the continuity equation $[6,7]$.

\subsection{Electromagnetic model}

Hypothesis From Ohm's law and Ampere's law for a non-magnetic medium we have

$$
\vec{\nabla} \wedge(\vec{\nabla} \wedge \vec{A})=\mu_{e} \vec{j}=-\sigma \mu_{e}\left(\vec{\nabla} V+\frac{\partial \vec{A}}{\partial t}-\vec{u} \wedge(\vec{\nabla} \wedge \vec{A})\right)
$$

As the magnetic Reynolds number $R_{m}$ is less than unity, we can neglect the term $-\sigma \vec{u} \wedge(\vec{\nabla} \wedge \vec{A})$ in equation (7). Indeed, the dimensionless number $R_{m}$ is defined as $R_{m}=\mu_{e} \sigma U h$, where $U$ is a characteristic velocity. It characterizes the ratio of the currents induced by flow to the currents induced by temporal variations of the electromagnetic field. Another relevant characteristic that follows from sinusoidal variations of the electromagnetic field is the electromagnetic skin depth $\delta=\sqrt{2 / \mu_{e} \sigma \omega}$. This length represents the diffusion depth of the electromagnetic field in the 
material at pulsation frequency $\omega$. The penetration depth can be described by introducing the shield number $R_{\omega}=2 e^{2} / \delta^{2}=\mu_{e} \sigma \omega e^{2}$ where $e$ is the thickness of material. The conductor elements (crucible, coil and base) have a thin electromagnetic skin depth in the usual frequency range $(300 \mathrm{kHz})$. Thus a decreasing exponential law can be used to calculate the electromagnetic variables. However, this law is not available within the glass bath.

Equations and resolution The electromagnetic model is based on these characteristics. The program called OPHELIE has been developed by the EPM-Madylam laboratory [8]. This program uses integral methods to solve the problem. The problem is defined by equations (8), (9) and (10) where $V$ and $\vec{j}$ are the unknowns.

$$
\begin{gathered}
\vec{\nabla} \cdot \vec{j}=0 \\
\oint \vec{\nabla} V \cdot d \vec{l}=0 \\
\vec{j}=-\sigma\left(\vec{\nabla} V+\frac{\partial \vec{A}}{\partial t}\right)
\end{gathered}
$$

The vector potential $\vec{A}$ is given by the Biot-Savart law (11).

$$
\vec{A}(M)=\frac{\mu_{e}}{4 \pi} \int_{V} \frac{\vec{j}}{r} d v
$$

The main advantages of this method are the possibility of reducing the mesh to electrically active parts and of solving equations with only two unknowns: one component of the current density vector $\vec{j}$ and the scalar potential $V$. In the conductor elements (crucible, coil and base) the mesh is limited to the surface and a decreasing exponential law is used to calculate the electromagnetic variables. Within the molten glass, the skin depth is thicker $\left(R_{\omega}=1\right)$ and a volume mesh is therefore created. The modelled cold crucible is three-dimensional and periodic in the azimuthal direction. Thus, only one water-cooled segment of the cold crucible is meshed. The others elements (molten glass, coil and base) are assumed to be axisymmetric. After integration, we obtain a system of linear equations. The matrix of the system is full, non-symmetric and complex. 


\subsection{Coupling}

Analysis shows that the phenomena are highly coupled because the physical properties of the glass vary greatly with temperature [9]. Coupled modelling is therefore necessary [1]. The values of physical properties are presented at $1473 \mathrm{~K}$ and in the temperature range of the glass bath in table 1.

Coupling is only applied for the calculations concerning the glass bath where the unknowns have to be calculated. The electrical conductivity and the density of the Joule power are used to couple the electromagnetism and the thermohydrodynamics. The general algorithm of coupling is given in figure 2 . As the electrical conductivity varies greatly with temperature, this variable is under-relaxed to avoid divergence of the solution. An interpolation between the FLUENT and OPHELIE programs is necessary because meshes are different from one problem to another. An in-house supervisor program runs successively and automatically controls the FLUENT and OPHELIE programs. The convergence criterions of each program are chosen by the user. The coupling iteration is controlled by a convergence criterion that is based on temperature changes between the last two iterates of the solution.

\section{Results and discussion}

The results presented in this part are normalized by the maximum numerical value of the variable. The temperature within the glass bath is about $1500 \mathrm{~K}$ and the total Joule power is $50 \mathrm{~kW}$. The numerical results are validated using experimental thermal results obtained from a vitrification pilot facility installed at Marcoule (France). Thermohydrodynamic phenomena are modified by the presence of this measurements system and the bath can no longer be assumed to be axisymmetric. Coupling was therefore achieved by first using 2D axisymmetric modelling without thermocouples. Then, the calculated distribution of the Joule power is directly injected in a three-dimensional 
calculation with thermocouples. This method was used because the presence of the thermocouples has a weak effect on the Joule power distribution in the melt.

\subsection{D-modelling}

For the 2D axisymmetric coupling, the thermohydrodynamic grid consists of 7000 structured cells. A boundary layer mesh is generated in regions of high thermal gradients close to the walls and the free surface. The electromagnetic structured grid contains 2500 nodes within the glass bath.

The first step is to test the sensitivity of the results to the heat transfer coefficient. This coefficient depends on experiments and particularly on the characteristics of the cold crucible: thickness of the walls, velocity and physical properties of the cooling water and physical properties of the cold crucible. The previous works for a glass bath in cold crucible arrangement use various values for this parameter. It is in the range of $100-300 \mathrm{~W} \cdot \mathrm{m}^{-2} \cdot \mathrm{K}^{-1}$ according to Saumabere [10] and it is estimated in Schiff [2] as $183 \mathrm{~W} \cdot \mathrm{m}^{-2} \cdot \mathrm{K}^{-1}$. More precisely, the approximate expression used by Schiff [3] gives a result of about $150 \mathrm{~W} \cdot \mathrm{m}^{-2} \cdot \mathrm{K}^{-1}$ for the present conditions. However, the geometry of the cold crucible and the total Joule power within the glass are different. Thus, the sensitivity study is carried out by analyzing the results of four cases where the heat transfer coefficient varies from 100 to $400 \mathrm{~W} \cdot \mathrm{m}^{-2} \cdot K^{-1}$. The various values tested are detailed in table 2 . In this study, the heat transfer coefficient of the free surface and the base does not change. The coefficient of the base is $35 \mathrm{~W} \cdot \mathrm{m}^{-2} \cdot K^{-1}$. Concerning the free surface, the average value can be derived from $N u=a R a^{b}$ in which $a$ and $b$ are constants. They are both dependent on the geometry of the system and the Rayleigh number $R a=g \beta_{a i r}\left(T_{s}-T_{a}\right) R^{3} / \nu_{a i r} \alpha_{a i r}$. The Rayleigh number is about $10^{9}$ in this study, the values for $a$ and $b$ are therefore 0.15 and 0.33 , respectively [11]. This results in a heat transfer coefficient of $20 \mathrm{~W} \cdot \mathrm{m}^{-2} \cdot \mathrm{K}^{-1}$.

Profiles of the temperature across the radius of the glass bath at a height of $0.5 \mathrm{~h}$ for cases 1,2 , 
3 and 4 are illustrated in figure 3 . We can show that the curves for the cases 2, 3 and 4 are different from the case 1 . This difference can be explained by the formation of a thin layer of solidified glass with higher heat transfer coefficients. In fact, this solid zone between the molten glass and the cooled walls creates a resistance superior to the resistance imposed by the heat transfer coefficient, the influence of the heat transfer coefficients can therefore be neglected. Consequently, it is necessary to choose the heat transfer coefficient to be superior to $200 \mathrm{~W} \cdot \mathrm{m}^{-2} \cdot \mathrm{K}^{-1}$ to describe the solidified layer. The shape of skull layer depends on the melt flow intensity and the physical properties of the glass. The limits of the solid zone for the four cases are presented in figure 4 . The glass is assumed to be solidified when the viscosity is higher than $10^{4} \mathrm{~Pa} . \mathrm{s}$, which corresponds to the viscosity at the flow point. The thickness of the skull layer varies on the millimeter to centimeter scale. The solidified zone is thicker near the corner and the base because the effects of natural convection are weaker in these zones. Finally, the profiles of the cases 2, 3, 4 are very close except near the cooled walls. Thus, the choice of the heat transfer coefficient is motivated by the measurements of temperature on the walls of the crucible. A similar study has been carried out to choose the heat transfer coefficient of the base wall. The values tested vary from 15 to 75 $W \cdot m^{-2} \cdot K^{-1}$. Results show that the coefficient has to be higher than $35 W \cdot m^{-2} \cdot K^{-1}$ to form the skull.

The figures 5 and 6 show power source distribution in vertical cross section respectively at the beginning of the coupling and after convergence. The calculation converges after about twenty coupling iterations. The differences between these two distributions underline the necessity to perform coupled modelling; the highest density of Joule power moves to the center of the bath during the coupling iterations. The highest density of Joule power is mainly located in the periphery of the upper zone of the melt (figure 6). This heat source drives the ascent of fluid to the free surface. Consequently, two-cell circulation is formed (figure 7). The descent of the fluid along the cooling 
water walls creates the peripheral cell. The main cell closes along the axis of the crucible and carries the cold glass from the surface to the bottom. The maximum values of velocity are reached in the upper region near the axis where the melt is colder. The melt movement created by the main cell deforms the isotherms in the central zone of the melt (figure 8). These two cells have been observed during experiments.

\subsection{Validation with 3D-modelling}

Once the 2D axisymmetric coupling has been performed, the calculated distribution of the Joule power (figure 6) is directly injected in a three-dimensional calculation with thermocouples. Four non-cooled thermocouples were set radially to acquire temperature fields in the glass. The locations of the thermocouples are illustrated in figures 9,10 and 11 on the vertical cross section of the glass bath where thermocouples are set. Temperatures are measured by plunging the thermocouples simultaneously into the bath. A calculation is therefore achieved for each position of the thermocouples. In this 3D-study, the device where thermocouples are set is totally modelled.

The calculation is performed with a $2 \mathrm{D}$ axisymmetric power source distribution however temperatures and velocities are no longer axisymmetric in one quarter of the glass bath around the thermocouples. The influence of thermocouples on thermohydrodynamics is visible in figures 9 , 10 and 11. The presence of the thermocouples decreases the area of the hot zone and moves it to the crucible walls. This can be explained by stagnation points on the thermocouples which lead to the cooling of the glass surrounding the thermocouples. More precisely, modelling shows that thermocouples lower the maximum temperature in the glass bath (see figures 12, 13 and 14). The comparison between the numerical data and the experimental measurements at the thermocouples 1,2 and 3 is shown in figures 12,13 and 14 , respectively. The numerical simulation gives results similar to those of experimental measurements except for thermocouple 3. This difference 
can be explained because the geometry of the inductor and thermal boundary conditions are not perfectly axisymetric due to the power supply connection and the angulary sectioned cooling system. Concerning the velocity field, validation is not possible in the molten glass because velocities can be measured experimentally only on the free surface. A comparison between numerical and experimental results shows good agreement in this zone. Transient modelling has been carried out to validate the steady state hypothesis. The steady state solution reached by integrating the time-dependent equations is similar to the steady state solution.

\section{Conclusions}

The vitrification process is continuously evolving to keep pace with new requirements. The process has been modelled to assist in the design of a cold-crucible vitrification facility. The model study has been designed to take into account the coupled electromagnetic, hydrodynamic and thermal phenomena. Results show that it is possible to directly inject an axisymmetric Joule power distribution in the 3D thermohydrodynamic calculation. This method shows good agreement between experimental and numerical results. The validation of numerical modelling has been carried out taking into account the measurement device.

\section{Nomenclature General symbols}

$A$ magnetic potential $\left(W e . m^{-1}\right)$

$C_{p}$ heat capacity $\left(J \cdot \mathrm{kg}^{-1} \cdot \mathrm{K}^{-1}\right)$

$d l$ elementary length $(m)$

$d v$ elementary volume $\left(\mathrm{m}^{3}\right)$

$e$ thickness of material $(m)$

$g$ gravitational acceleration $\left(m . s^{-2}\right)$ 
$h$ height of the glass bath $(m)$

$h_{s}$ heat transfer coefficient of the free surface $\left(W \cdot m^{-2} \cdot K^{-1}\right)$

$h_{w}$ heat transfer coefficient of the wall (base or crucible) $\left(W \cdot m^{-2} \cdot K^{-1}\right)$

$j$ current density $\left(A . m^{-2}\right)$

$p$ pressure $(P a)$

$\operatorname{Pr}$ Prandtl number (-)

$Q_{t h}$ density of the Joule power $\left(W \cdot m^{-3}\right)$

$r$ distance between the elementary volume $d v$ and the point $M(m)$

$R a$ Rayleigh number (-)

$R_{m}$ magnetic Reynolds number (-)

$R_{\omega}$ shield number (-)

$t$ time $(s)$

$T$ temperature $(K)$

$T_{a}$ temperature outside the induction furnace $(K)$

$T_{c}$ cooling water temperature $(K)$

$T_{s}$ free surface temperature of the glass bath $(K)$

$T_{w}$ glass temperature at the wall (base or crucible) $(K)$

$T_{0}$ operating temperature $(K)$

$u$ velocity $\left(m . s^{-1}\right)$

$V$ electrical scalar potential $(V)$

$z$ vertical direction $(m)$

Greek letters

$\alpha$ thermal diffusivity $\left(m^{2} \cdot s^{-1}\right)$ 
$\beta$ coefficient of thermal expansion $\left(K^{-1}\right)$

$\delta$ electromagnetic skin depth $(m)$

$\epsilon$ emissivity of the glass (-)

$\phi$ heat flux $\left(W \cdot m^{-2}\right)$

$\lambda$ thermal conductivity $\left(W \cdot m^{-1} \cdot K^{-1}\right)$

$\mu$ dynamic viscosity (Pa.s)

$\mu_{e}$ magnetic permeability $\left(\mu_{e}=4 \pi 10^{-7} H \cdot m^{-1}\right)$

$\nu$ kinematic viscosity $\left(m^{2} \cdot s^{-1}\right)$

$\rho$ density $\left(k g \cdot \mathrm{m}^{-3}\right)$

$\rho_{0}$ constant density $\left(\mathrm{kg} \cdot \mathrm{m}^{-3}\right)$

$\sigma$ electrical conductivity $\left(\Omega^{-1} \cdot m^{-1}\right)$

$\sigma_{s b}$ Stefan-Boltzmann constant $\left(\sigma_{s b}=5 \cdot 67 \cdot 10^{-8} W \cdot m^{-2} \cdot K^{-4}\right)$

$\omega$ pulsation of the current $\left(s^{-1}\right)$

\section{References}

[1] S. SERVANT, D. SAUMABERE, A. GAGNOUD, and Y. DU TERRAIL. Malice : un logiciel couplant la méthode intégrale et la méthode des éléments finis. application à la fusion des oxydes en creuset froid. Journal de Physique III, 2(11):1991-2004, 1992.

[2] V. K. SCHIFF. Mathematical modelling of the complex heat exchange of a glass melt in a cylindrical induction furnace. Journal of Optical Technology, 67(9):787-791, September 2000.

[3] V. K. SCHIFF, A. N. ZAMYATIN, and A. A. ZHILIN. Numerical simulation of thermal 
convection of a glass melt in a cylindrical induction furnace. Glass Science and Technology, 69(12):379-86, September 1996.

[4] O. M. G. C. OP DEN CAMP and V. O. AUME. Advanced forehearth design by means of mathematical modeling. In The 18th International Congress on Glass, San Francisco, California, 5-10 July 1998.

[5] M. ROSCINI. Fusion de verres par induction : étude électromagnétique et thermohydraulique. $\mathrm{PhD}$ thesis, I.N.P.G., 1990.

[6] S. V. PATANKAR. Numerical Heat Transfer and Fluid Flow. Hemisphere, Washington D.C., 1980.

[7] Fluent Incorporated. Fluent 6 Users Guide. 2004.

[8] A. GAGNOUD and I. LECLERCQ. Electromagnetic modelling of induction melting devices in cold crucibles. In IEEE Trans. Magn., volume 24, pages 573-575, 1988.

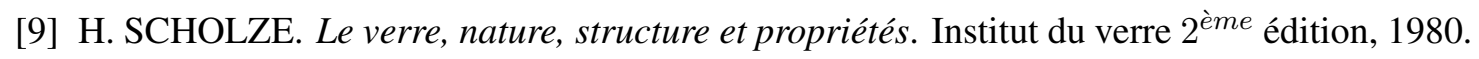

[10] D. SAUMABERE. Modélisation numérique magnéto-thermique avec prise en compte du transfert radiatif dans les procédés d'élaboration des verres par induction en creuset froid. PhD thesis, I.N.P.G., 1994.

[11] F. P. INCROPERA and D. P. DEWITT. Fundamentals of heat and mass transfer. J. Wiley \& Sons, 1996. 


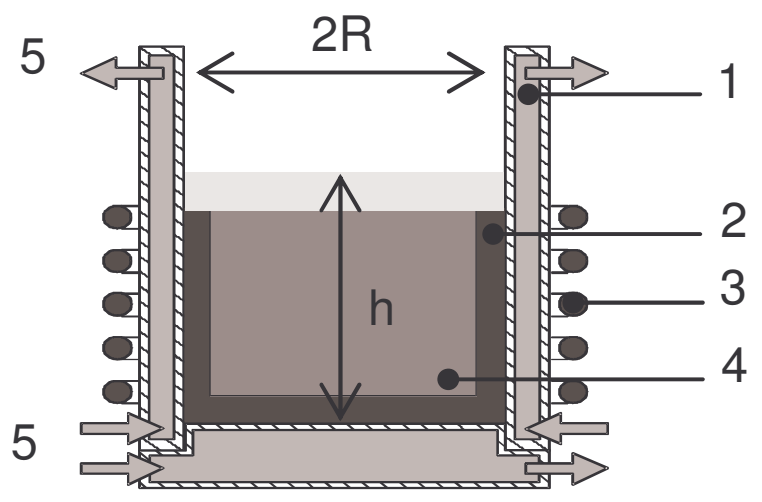

Figure 1: Cold crucible. 1: water-cooled segment, 2: solidified glass, 3: inductor, 4: molten glass, 5: cooling water. $h$ height of the glass bath, $R$ radius of the glass bath

\begin{tabular}{ccc}
\hline \hline Physical properties & at $1473 \mathrm{~K}$ & $\begin{array}{c}\text { variations in the temperature range } \\
\text { of the glass bath }\end{array}$ \\
\hline Density, $\rho_{0}\left(\mathrm{~kg} \cdot \mathrm{m}^{-3}\right)$ & 2750 & - \\
Dynamic Viscosity, $\mu(P a \cdot s)$ & 4 & $1-10^{8}$ \\
Heat Capacity, $C_{p}\left(\mathrm{~J} \cdot \mathrm{kg}^{-1} \cdot \mathrm{K}^{-1}\right)$ & 1150 & $750-1200$ \\
Thermal conductivity, $\lambda\left(\mathrm{W} \cdot \mathrm{m}^{-1} \cdot \mathrm{K}^{-1}\right)$ & 4 & $1-5$ \\
Electrical conductivity, $\sigma\left(\Omega^{-1} \cdot \mathrm{m}^{-1}\right)$ & 16 & $10^{-6}-30$ \\
Thermal expansion coefficient, $\beta\left(\mathrm{K}^{-1}\right)$ & $10^{-5}$ & - \\
\hline \hline
\end{tabular}

Table 1: Values of physical properties at $1473 \mathrm{~K}$ and in the temperature range of the glass bath.

\begin{tabular}{cc}
\hline \hline CASE & $\begin{array}{c}\text { Heat transfer coefficient } \\
W \cdot m^{-2} \cdot K^{-1}\end{array}$ \\
\hline 1 & 100 \\
2 & 200 \\
3 & 300 \\
4 & 400 \\
\hline \hline
\end{tabular}

Table 2: Values of the heat transfer coefficient for the various cases 


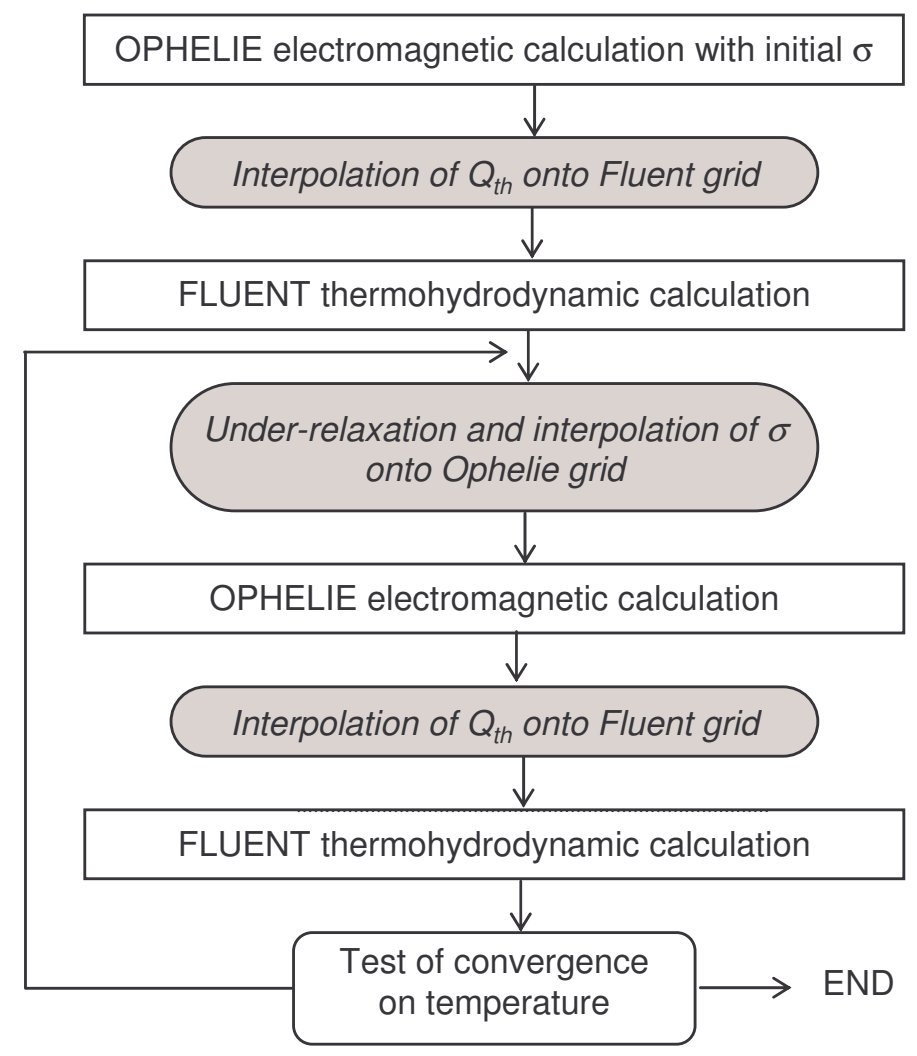

Figure 2: The general algorithm for coupling

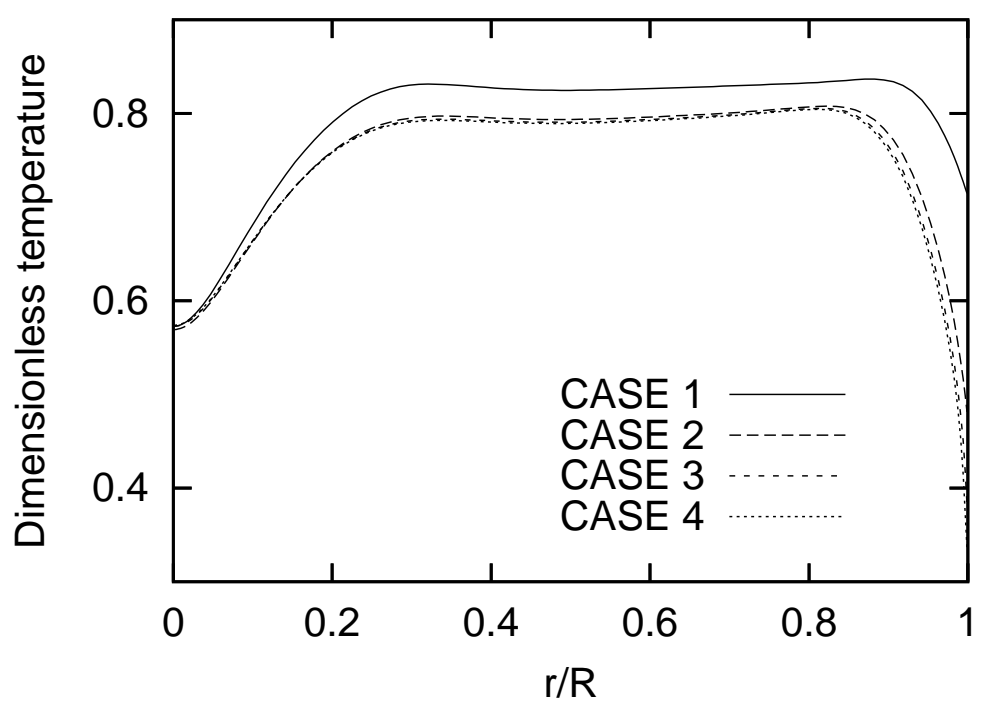

Figure 3: Comparison of calculated temperatures between CASE 1, 2, 3 and 4 at a height of $0.5 \mathrm{~h}$ 


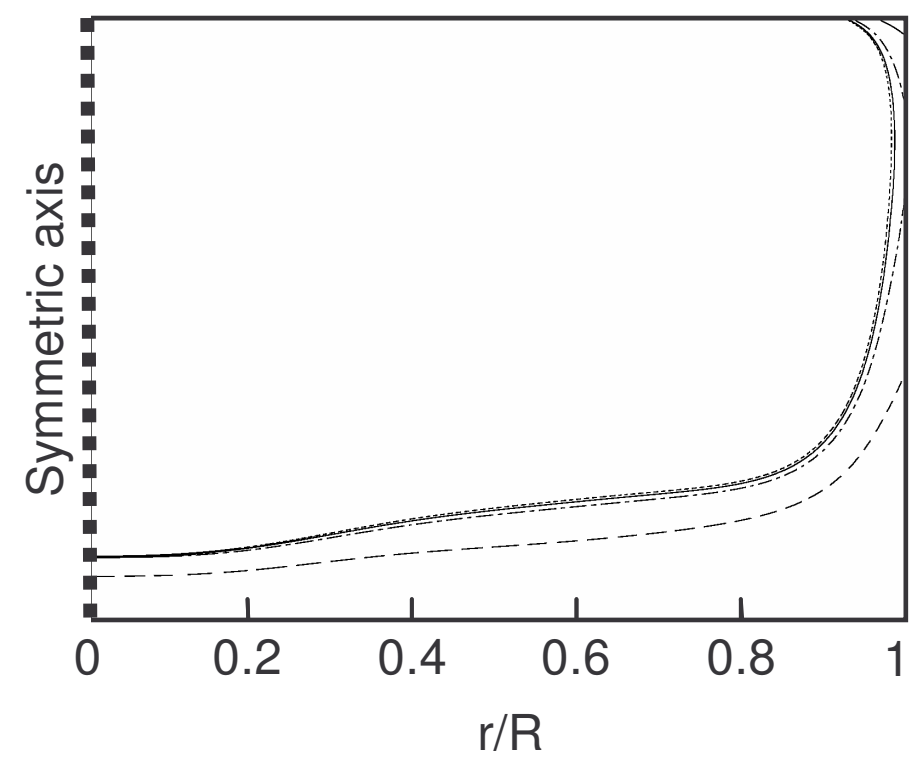

Figure 4: Shape of skull layer. CASE 1: - - , CASE 2: - - - CASE 3: - , CASE 4: $\cdots$

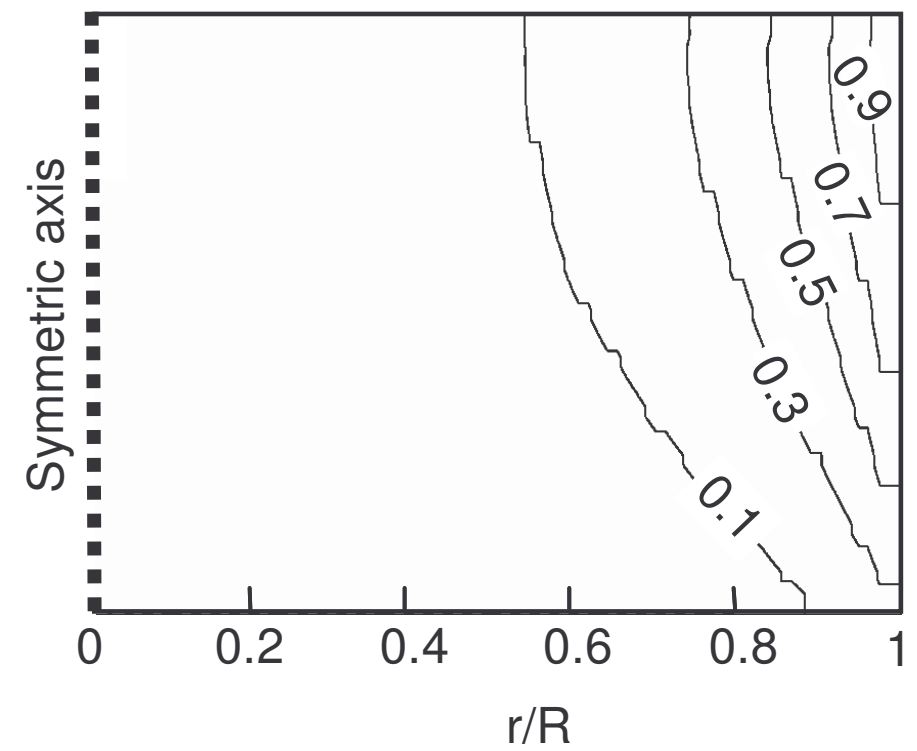

Figure 5: Dimensionless power source distribution in vertical cross section. These results are obtained at the $5^{\text {th }}$ coupling iteration by $2 \mathrm{D}$ axisymmetric coupling. 


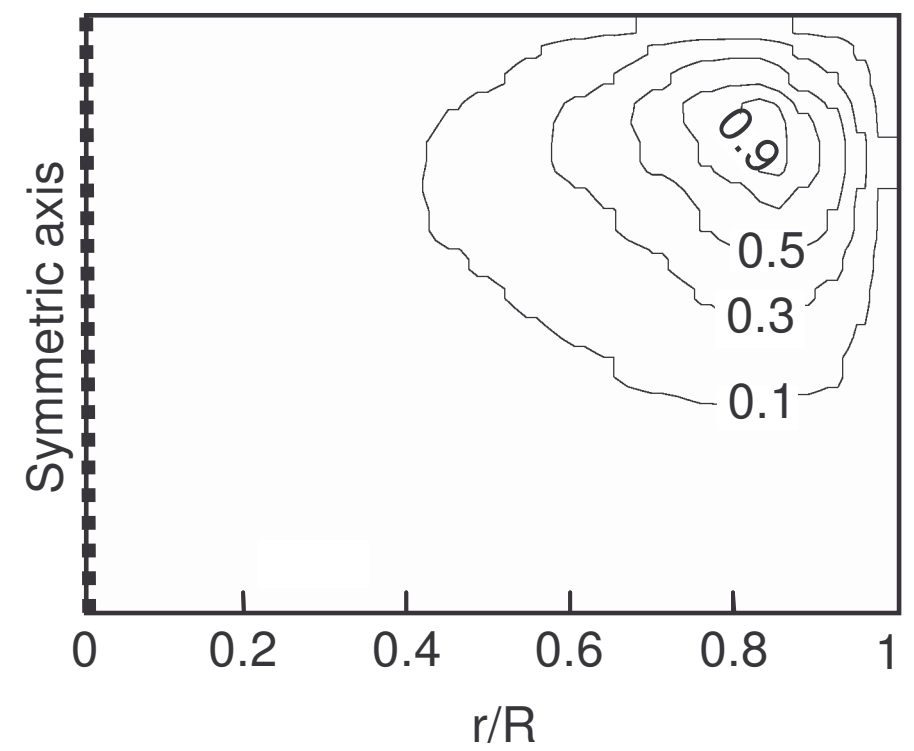

Figure 6: Dimensionless power source distribution in vertical cross section. These results are obtained at convergence by $2 \mathrm{D}$ axisymmetric coupling.

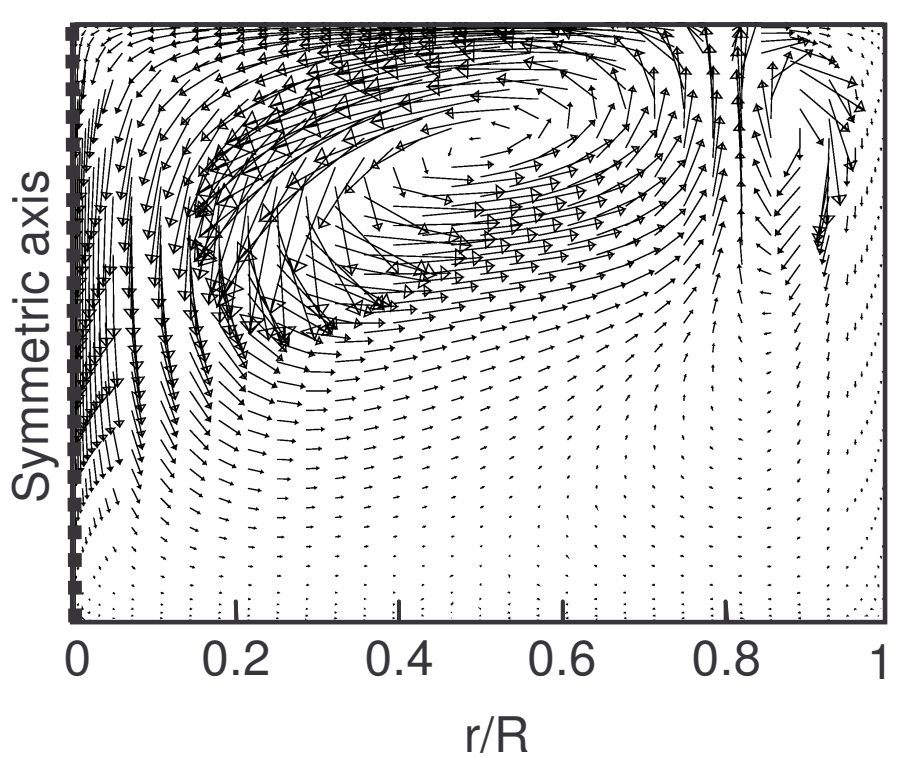

Figure 7: Flow pattern in vertical cross section. Velocities are obtained by 2D axisymmetric coupling. 


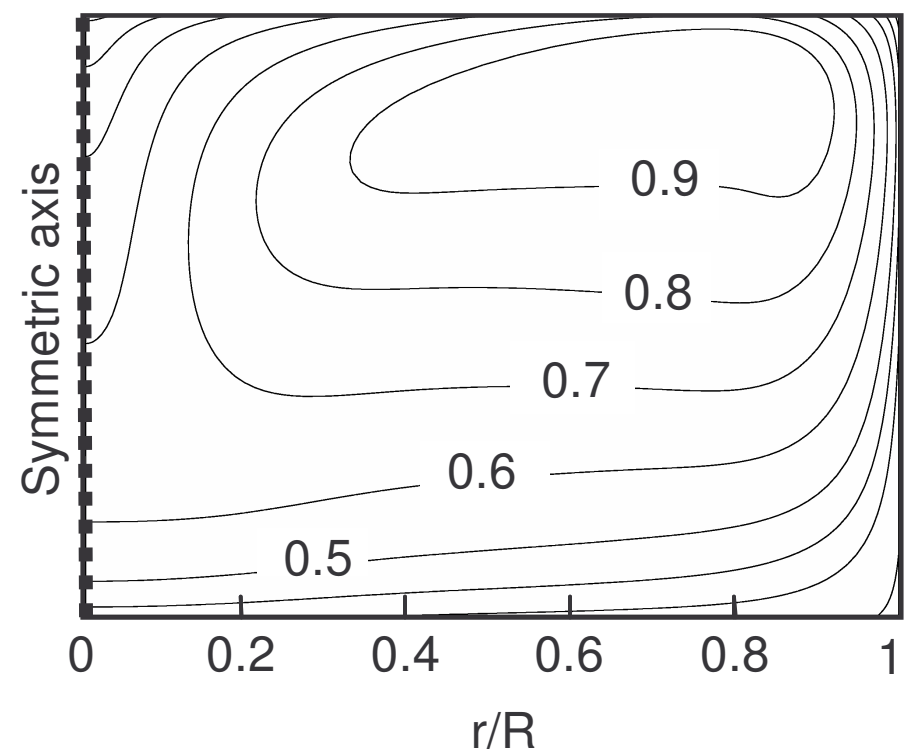

Figure 8: Dimensionless temperature distribution in vertical cross section. These results are obtained by 2D axisymmetric coupling.

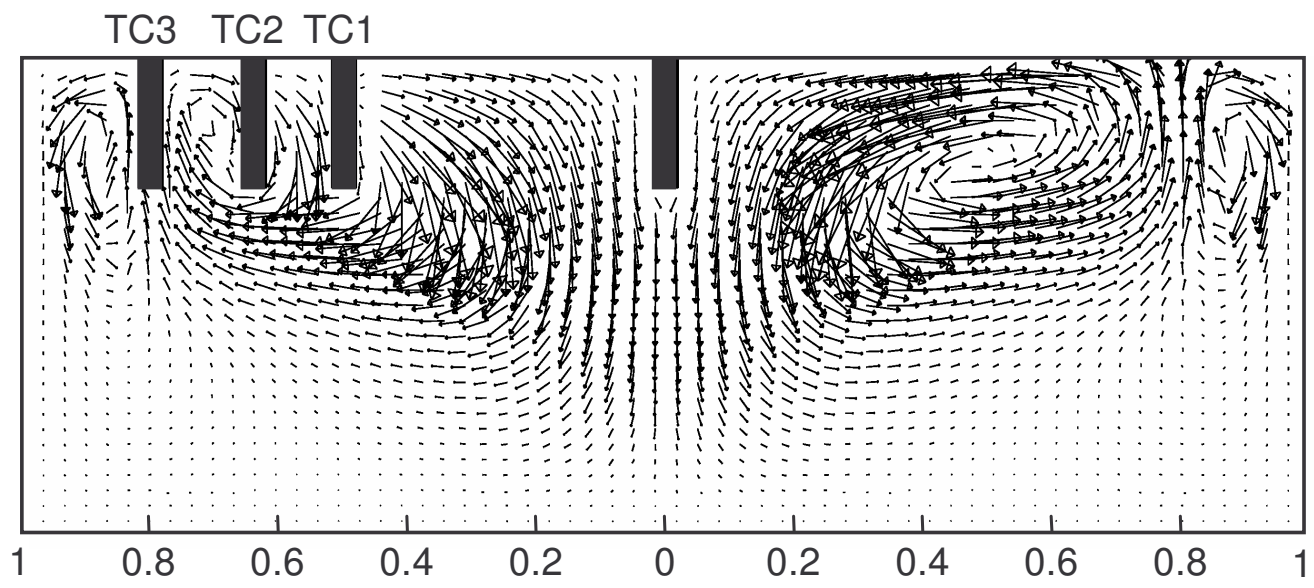

Figure 9: Flow pattern in the vertical cross section where thermocouples are set radially. Velocities are obtained by 3D thermal and hydrodynamic calculation. The power source distribution injected is calculated by the 2D-axisymmetric coupling. 


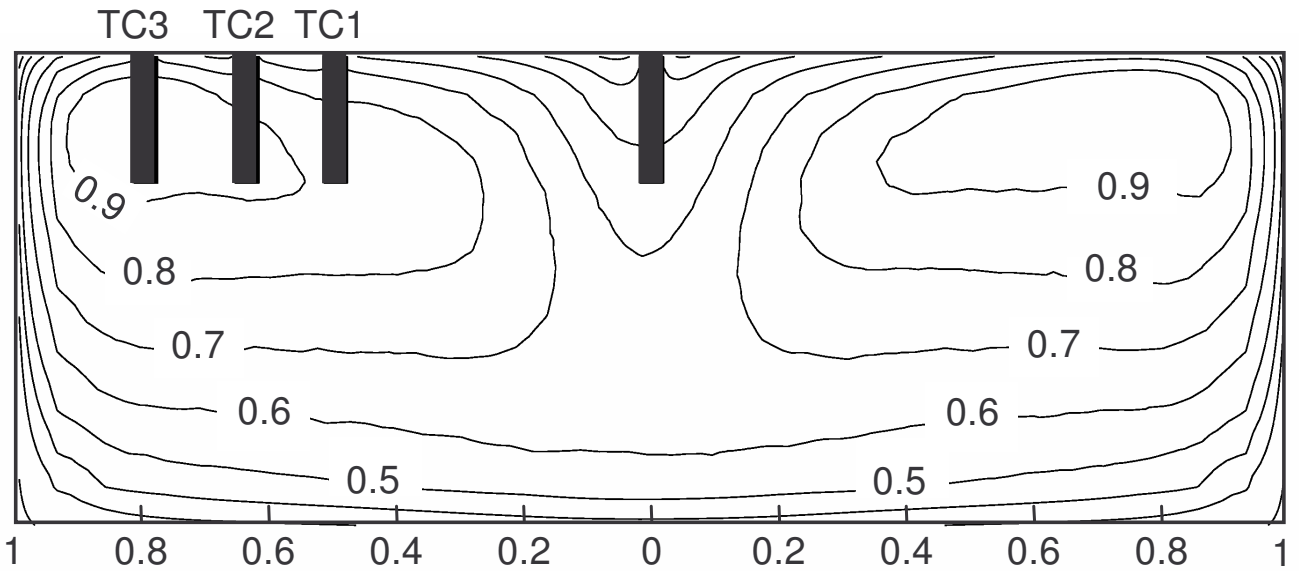

Figure 10: Dimensionless temperature distribution in the vertical cross section where thermocouples are set radially. Temperatures are obtained by 3D thermal and hydrodynamic calculation. The power source distribution injected is calculated by the $2 \mathrm{D}$-axisymmetric coupling.

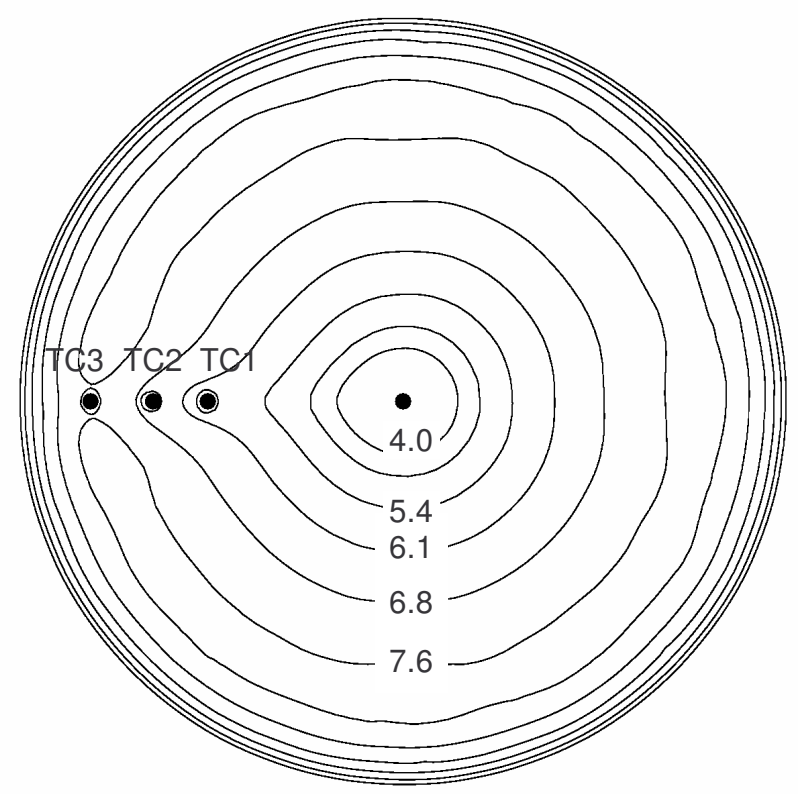

Figure 11: Dimensionless temperature distribution at the free surface. Temperatures are obtained by 3D thermal and hydrodynamic calculation. The power source distribution injected is calculated by the $2 \mathrm{D}$-axisymmetric coupling. 


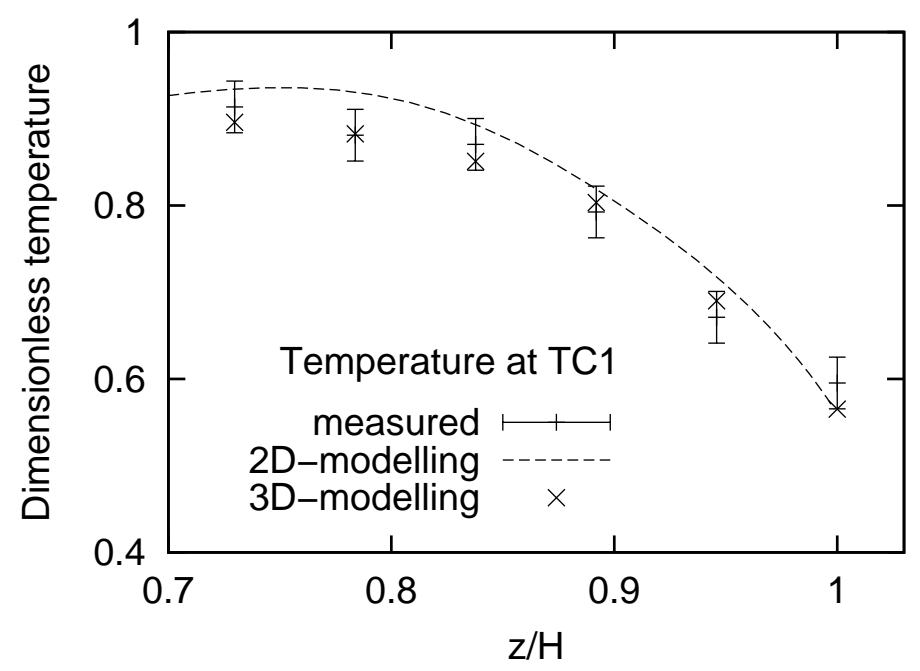

Figure 12: Dimensionless temperatures at the TC1. Temperatures measured and calculated by 2D and 3D modelling.

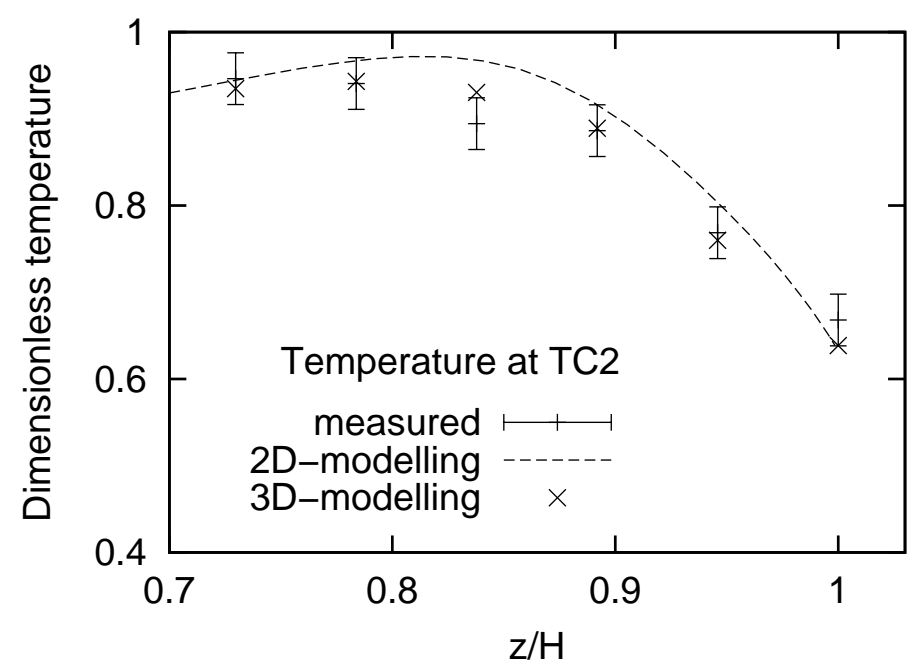

Figure 13: Dimensionless temperatures at the TC2. Temperatures measured and calculated by 2D and 3D modelling. 


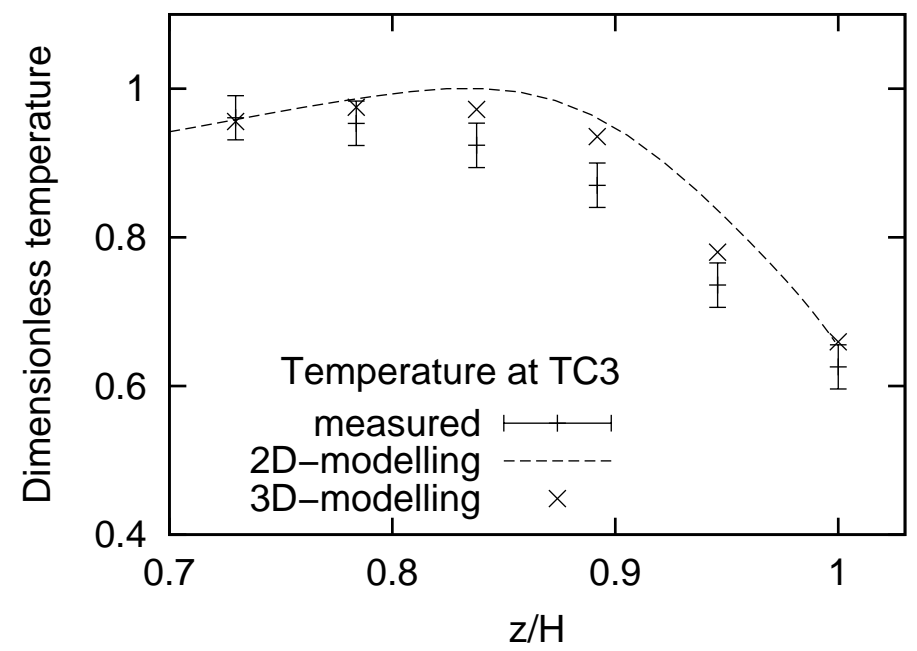

Figure 14: Dimensionless temperatures at the TC3. Temperatures measured and calculated by 2D and 3D modelling. 